\title{
Многоуровневая запись в тонких пленках $\mathrm{Ge}_{2} \mathrm{Sb}_{2} \mathrm{Te}_{5}$
}

\author{
(ㄱ С.А. Фефелов ${ }^{1}$, Л.П. Казакова ${ }^{1,2}$, Н.А. Богословский ${ }^{1}$, А.Б. Былев ${ }^{2}$, А.О. Якубов ${ }^{3}$ \\ ${ }^{1}$ Физико-технический институт им. А.Ф. Иоффе Российской академии наук, \\ 194021 Санкт-Петербург, Россия \\ ${ }^{2}$ Государственный лесотехнический университет им. С.М. Кирова, \\ 194021 Санкт-Петербург, Россия \\ ${ }^{3}$ Национальный исследовательский университет „МИЭТ“, \\ 124498 Зеленоград, Россия \\ E-mail: s.fefelov@list.ru
}

Поступила в Редакцию 31 октября 2019 г.

В окончательной редакции 25 ноября 2019 г.

Принята к публикации 25 ноября 2019 г.

\begin{abstract}
Проведены исследования вольт-амперных характеристик, полученных на тонких пленках $\mathrm{Ge}_{2} \mathrm{Sb}_{2} \mathrm{Te}_{5}$ в токовой моде. Установлен эффект многоуровневой записи при последовательной подаче на образец импульсов тока с возрастающим максимальным значением. Показано, что этот эффект может быть связан с расширением канала памяти. Получена оценка размера канала памяти. Сделан вывод о возможности использования пленок $\mathrm{Ge}_{2} \mathrm{Sb}_{2} \mathrm{Te}_{5}$ в качестве мемристора.
\end{abstract}

Ключевые слова: халькогенидные стеклообразные полупроводники, эффект переключения, фазовая память, шнур тока, многоуровневая запись.

DOI: 10.21883/FTP.2020.04.49144.9301

\section{1. Введение}

Халькогенидные стеклообразные полупроводники (ХCП) системы $\mathrm{Ge}-\mathrm{Sb}-\mathrm{Te}$ на протяжении последних двух десятилетий привлекают внимание исследователей как материал, перспективный для использования в элементах памяти, работающей на фазовом переходе халькогенидное стекло-кристалл, так называемой фазовой памяти. В настоящее время они находят все более широкое применение в этом качестве. Однако, несмотря на интенсивные и всесторонние исследования, механизм эффекта памяти все еще недостаточно изучен. Кроме того, в результате исследований открываются все новые свойства этих материалов. Так, в работах $[1,2]$ говорится о возможности создания на их основе ячеек с многоуровневой памятью. В данной работе приводятся результаты, полученные в наших исследованиях, поддерживающие это мнение. Они демонстрируют эффект многоуровневой записи в тонких пленках $\mathrm{Ge}_{2} \mathrm{Sb}_{2} \mathrm{Te}_{5}$.

\section{2. Образцы и методика эксперимента}

Образцы для измерений представляли собой тонкопленочные структуры типа „сандвич“, которые изготавливались магнетронным напылением ХСП состава $\mathrm{Ge}_{2} \mathrm{Sb}_{2} \mathrm{Te}_{5}$ на подложки из кремния с окисной пленкой $\mathrm{SiO}_{2}$ толщиной 1 мкм и проводящим покрытием, которое служило нижним электродом. Проводящее покрытие состояло из слоя TiN толщиной 30 нм и напыленных затем слоев $W$ толщиной 50 нм и TiN толщиной 15 нм. Толщина слоя $\mathrm{Ge}_{2} \mathrm{Sb}_{2} \mathrm{Te}_{5}$ для всех образцов была равна $d=130$ нм. Верхний электрод был прижимной, точечный из золота с площадью контакта $\sim 10^{4} \mathrm{~cm}^{2}$.

Измерения проводились как на свеженапыленных образцах, так и на отожженных в течение 4ч при температуре $100^{\circ} \mathrm{C}$. При исследовании вольт-амперных характеристик (BAX) использовалась измерительная цепь с генератором тока $[3,4]$. На образец подавалась серия треугольных токовых импульсов с последовательно увеличивающимися максимальными значениями тока $\left(I_{\max }\right)$. Измерения проводились при следующих максимальных значениях тока, подаваемого на образец: 6.5, 100, 200, $565,1200,1900,3700$ и 8200 мкА. На образце регистрировалось падение напряжения $V$, величина которого определяется сопротивлением образца. Для построения BAX использовались осциллограммы $V(t)$. Значения сопротивлений определялись на линейном участке ВАХ.

\section{3. Экспериментальные результаты и их обсуждение}

На рис. 1 представлены осциллограммы напряжения, полученные на свеженапыленном образце $\mathrm{Ge}_{2} \mathrm{Sb}_{2} \mathrm{Te}_{5}$ при последовательной подаче 4 импульсов тока, значения $I_{\max }$ для которых возрастало от 200 до 8200 мкА. На рис. 2 приведены соответствующие ВАХ. Как видно из осциллограммы, при каждом импульсе наблюдалось скачкообразное уменьшение напряжения на образце, связанное с переходом в состояние с меньшим сопротивлением. При этом с увеличением $I_{\max }$ этот переход происходил при более низком значении напряжения на образце.

Из рис. 2 видно, что при подаче на образец каждого последующего импульса тока с возросшим значени- 
ем $I_{\max }$ прямая ветвь ВАХ, соответствующая высокоомному состоянию образца, идет по обратной ветви предыдущей $\mathrm{BAX}$, соответствующей низкоомному его состоянию, до тех пор, пока ток в образце не превышает $I_{\max }$ предыдущего импульса. Каждый следующий переход в новое низкоомное состояние происходил при превышении текущим значением тока $I_{\max }$ предшествующего импульса. Из этого следует, что образец остается в состоянии с низким сопротивлением после окончания импульса, т.е. образец запоминает низкоомное состояние.

Для объяснения нелинейности ВАХ и эффекта переключения в ХСП ранее в работах [5-7] была предложена электронно-тепловая модель. В рамках этой модели проведено численное моделирование процесса переключения и показано, что при резком переходе в низкоомное состояние в достаточно большом образце образуется шнур тока с высокой температурой [8]. В работе [9] была получена оценка характерной температуры шнура тока $T_{c o} \simeq 300^{\circ} \mathrm{C}$. Это значение близко к температуре фазового перехода в кристаллическое состояние, что согласуется с представлениями о том, что в области с высокой температурой внутри шнура тока, образующегося после перехода в новое низкоомное состояние, происходит кристаллизация образца. В результате формируется состояние (канал) памяти.

Используя ВАХ на ее линейном участке (рис. 2), можно оценить величину сопротивления $(R)$ сформированных каналов памяти при каждом переходе в новое состояние. Проведенная оценка показала, что значение $R$ уменьшалось при каждом последующем переходе и изменялось, соответственно, от 22 до 1.4 кОм.

Как видно из рис. 1, на осциллограммах напряжения на образце после каждого перехода наблюдается более или менее протяженный во времени участок постоянного напряжения (плато), который, видимо, связан с процессом формирования состояния памяти. Так как при этом ток в образце возрастает, то, очевидно, что его сопротивление уменьшается, откуда следует то, что шнур имеет постоянную плотность тока, соответствующую $I_{\max }$ предшествующего импульса тока. Следовательно, площадь поперечного сечения шнура $S$ возрастает с ростом силы тока в образце. Полагая, что при подаче на образец каждого импульса тока переход в новое низкоомное состояние происходит в области аморфной фазы, прилегающей к шнуру тока (т. е. ток через образец, $I=I_{a}+I_{c o}$, где $I_{a}$ и $I_{c o}-$ токи через аморфную область и по шнуру соответственно), и на основании того факта, что при переходе происходит резкое понижение напряжения (рис. 1,2), нами была проведена оценка размеров сформированного после каждого перехода канала памяти.

С помощью несложных вычислений, использующих закон Ома и выполняющееся для шнура тока соотношение $R S=\rho d=$ const, где $\rho-$ удельное сопротивление, были получены следующие формулы для токов через аморфную область и через шнур после перехода в новое

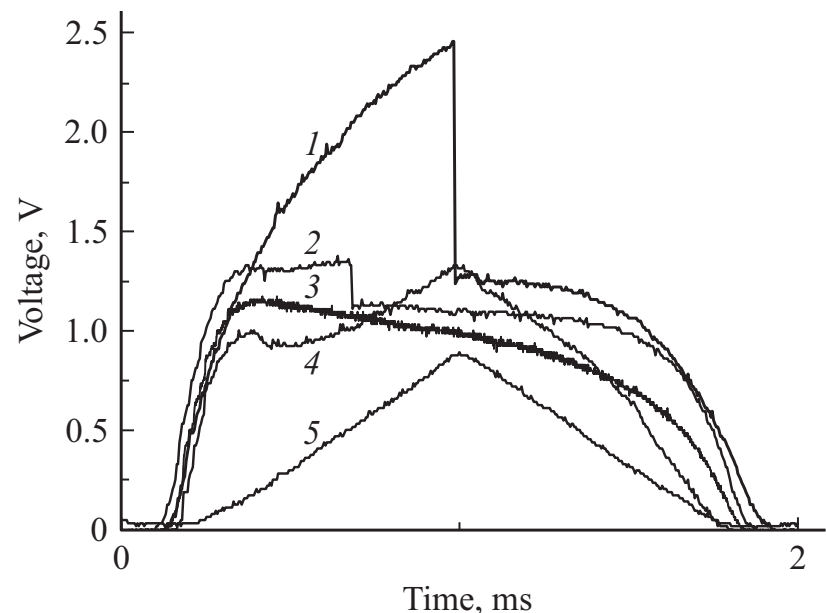

Рис. 1. Совмещенные осциллограммы напряжений на свеженапыленном образце для пяти импульсов тока, подаваемых на образец со значениями $I_{\max }$, мкА: $1-200,2-565,3-1200$, 4 - 8200; 5 - форма импульса тока (не в масштабе) синхронизирована во времени с импульсами напряжения.

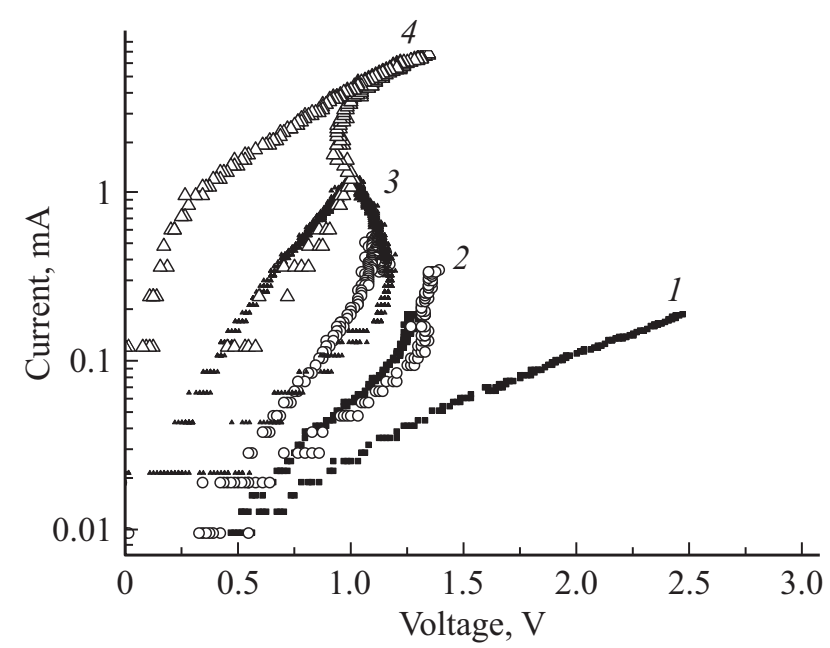

Рис. 2. BAX, полученные на свеженапыленном образце, соответствующие четырем подаваемым на образец импульсам тока со значениями $I_{\max }$, мкА: $1-200,2-565,3-1200$, $4-8200$.

состояние, а также для площади поперечного сечения шнура $\left(S_{c o}\right)$ :

$$
I_{a}=\left(I_{1} / V_{1}\right) V_{2} \quad \text { и } \quad S_{c o}=S_{1}=I_{1}\left(V_{1}-V_{2}\right) d \rho / V_{1} V_{2},
$$

где $V_{1}$ и $V_{2}$ - напряжения на образце в момент перехода и после него соответственно. Так как из эксперимента (рис. 1) $V_{1}=2.5 \mathrm{~B}, V_{2}=1.25 \mathrm{~B}, I_{1}=200$ мкА, то находим из формул, что $I_{a}=I=100$ мкА и $S_{1}=10^{-2}$ мкм $^{2}$ при $\rho=0.1$ Ом $\cdot$ см $[10]$.

Таким образом, в результате получаем оценку для радиуса сформированного после первого перехода канала памяти $r_{1}=0.1$ мкм. Используя величины сопротивлений, определенные выше из ВАХ, получаем также 


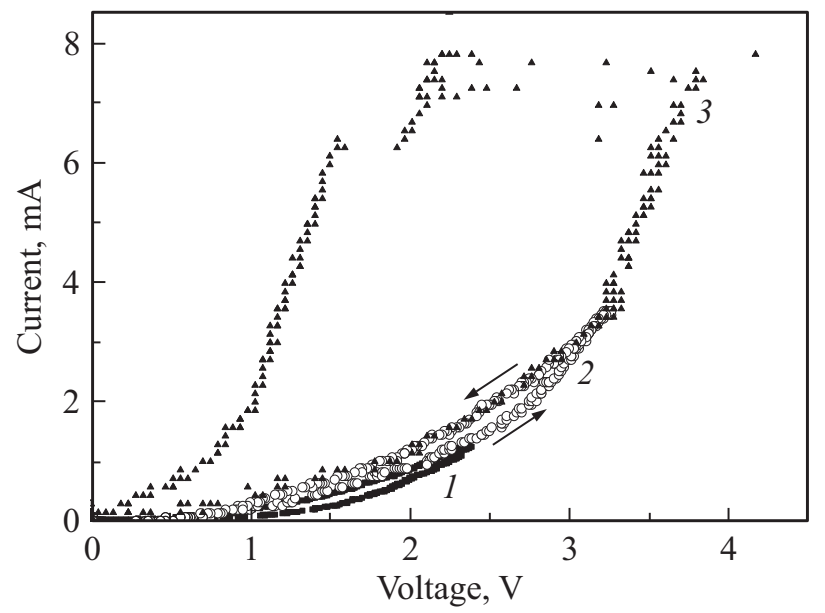

Рис. 3. ВАХ, полученные на отожженном образце, соответствующие трем подаваемым на образец импульсам тока со значениями $I_{\max }$, мкА: $1-1200,2-3700,3-8200$.

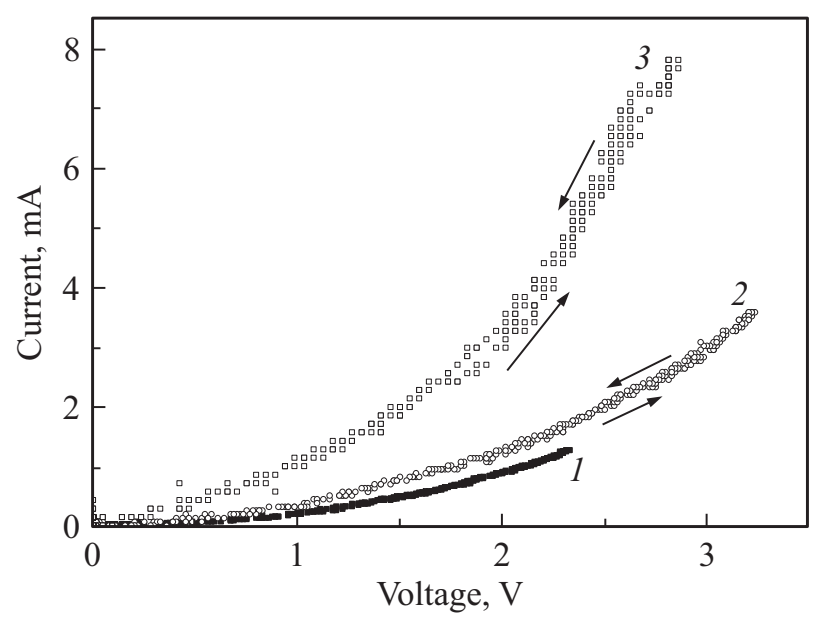

Рис. 4. ВАХ, полученные на отожженном образце, соответствующие трем повторно подаваемым на образец импульсам тока со значениями $I_{\max }$, мкА: $1-1200,2-3700,3-8200$.

оценки для радиусов сформированных после следующих переходов каналов памяти: $r_{2}=0.15$ мкм, $r_{3}=0.3$ мкм, $r_{4}=0.4$ мкм.

Полученный результат свидетельствует о том, что в момент прохождения через образец импульса тока в образце формируется проводящий канал, размеры которого зависят от величины максимального тока в импульсе.

На рис. 3 приведены ВАХ, полученные на отожженном образце при трех последовательно поданных на образец импульсах тока, значение $I_{\max }$ которых возрастало от 1.2 до 8.2 мА. Из рисунка видно, что в этом случае переход в новое состояние происходил при более высоких значениях напряжения и $I_{\max }$.

Характерной особенностью ВАХ, полученных на отожженных образцах, является то, что переход в низкоомное состояние обычно не сопровождается скачкооб- разным изменением напряжения, а происходит плавно. Исследования показали, что в случае отожженных образцов скачкообразный переход наблюдается значительно реже, чем в случае свеженапыленных (20 и 80\% соответственно).

Было установлено, что отожженные образцы по сравнению со свеженапыленными обладали более высоким сопротивлением и имели большую энергию активации проводимости. При повторной подаче импульсов как на отожженные, так и на свеженапыленные образцы скачкообразные переходы не наблюдались, прямые и обратные ветви ВАХ совпадали (рис. 4). Это говорит о том, что в образце сформировался кристаллический канал, который сохраняется и после окончания импульса. Размер канала и сопротивление образца определяются максимальным значением тока в импульсе. Таким образом, образец ведет себя как мемристор.

\section{4. Заключение}

В результате проведенной работы исследованы ВАХ, измеренные в режиме генератора тока на свеженапыленных и отожженных образцах $\mathrm{Ge}_{2} \mathrm{Sb}_{2} \mathrm{Te}_{5}$.

Установлено, что в случае отожженных образцов скачкообразный переход в новое низкоомное состояние наблюдался значительно реже, чем в случае свеженапыленных (20 и 80\% соответственно).

Было установлено, что отожженные образцы по сравнению со свеженапыленными обладали более высоким сопротивлением и имели бо́льшую энергию активации проводимости.

Установлен эффект многоуровневой записи в тонких пленках $\mathrm{Ge}_{2} \mathrm{Sb}_{2} \mathrm{Te}_{5}$.

Показано, что этот эффект может быть связан с расширением шнура тока. Сделана оценка размера шнура тока, которая показала, что его радиус возрастал от 0.1 до 0.4 мкм при изменении максимальной величины подаваемого на образец импульса тока от 200 до 8200 мкА.

Показано, что образцы состава $\mathrm{Ge}_{2} \mathrm{Sb}_{2} \mathrm{Te}_{5}$ могут работать как мемристоры.

\section{Конфликт интересов}

Авторы заявляют об отсутствии конфликта интересов.

\section{Список литературы}

[1] A. Athmanathan, M. Stanisavljevic, N. Papandreou, H. Pozidis, E. Eleftheriou. IEEE JETCAS, 6, 87 (2016).

[2] T. Nirschl, J.B. Philipp, T.D. Happ, G.W. Burr, B. Rajendran, M.-H. Lee, A. Schrott, M. Yang, M. Breitwisch, C.-F. Chen, E. Joseph, M. Lamorey, R. Cheek, S.-H. Chen, S. Zaidj, S. Raoux, Y.C. Chen, Y. Zhu, R. Bergmann, H.-L. Lung, C. Lam. Techn. Dig. Int. Electron Dev. Meet (IEDM Washington, December 10-12, United States, 2007) p. 461. 
[3] С.А. Фефелов, Л.П. Казакова, С.А. Яковлев, С.А. Козюхин, К.Д. Цэндин. Тр. Междунар. симп. МФГФП-1 „Физика межсбазных грании, и базовые переходы“ (Ростов-н/Д., Россия, 2011) с. 155.

[4] С.А. Фефелов, Л.П. Казакова, С.А. Козюхин, К.Д. Цэндин, Д. Арсова, В. Памукчиева. ЖТФ, 84, 80 (2014).

[5] Н.А. Богословский, К.Д. Цэндин. ФТП, 43 (10), 1378 (2009).

[6] N.A. Bogoslovskij, K.D. Tsendin. J. Non-Cryst. Sol., 357, 992 (2011).

[7] N. Bogoslovskiy. Phys. Status Solidi B, 250 (8), 1563 (2013).

[8] N. Bogoslovskiy, K. Tsendin. Solid-State Electron., 129, 10 (2017).

[9] С.А. Фефелов, Л.П. Казакова, Н.А. Богословский, К.Д. Цэндин. ФТП, 52 (12), 1503 (2018).

[10] T. Kato, K. Tanaka. Jpn. J. Appl. Phys., 44 (10), 7340 (2005).

Редактор Г.А. Оганесян

\section{Multilevel recording in $\mathrm{Ge}_{2} \mathrm{Sb}_{2} \mathrm{Te}_{5}$ thin-films}

S.A. Fefelov' ${ }^{1}$, L.P. Kazakova ${ }^{1,2}$, N.A. Bogoslovskiy ${ }^{1}$, A.B. Bylev ${ }^{2}$, A.O. Yakubov ${ }^{3}$

${ }^{1}$ Ioffe Institute,

194021 St. Petersburg, Russia

2 St. Petersburg State Forest Technical University,

194021 St. Petersburg, Russia

${ }^{3}$ National Research University

of Electronic Technology,

124498 Zelenograd, Russia

Abstract $I-V$ characteristics obtained on $\mathrm{Ge}_{2} \mathrm{Sb}_{2} \mathrm{Te}_{5}$ thin films in the current mode were studied. The effect of multilevel recording was established upon sequentially applying to the sample current pulses with increasing maximum value. It was shown that this effect can be associated with expansion of the memory channel. An estimate of the channel size is obtained. It is concluded that $\mathrm{Ge}_{2} \mathrm{Sb}_{2} \mathrm{Te}_{5}$ films can be used as a memristor. 